Volume 10, Nomor 2, November 2018, pp 199-211 Copyright (C) 2017 Jurnal Akuntansi Maranatha, Program Studi Akuntansi, Fakultas Ekonomi, Universitas Kristen Maranatha. ISSN 2085-8698 | e-ISSN 2598-4977. http://journal.maranatha.edu

\title{
Pengaruh Komitmen Organisasional Dan Budaya Organisasi Terhadap Organizational Citizenship Behaviour
}

\author{
Yunita Christy \\ Fakultas Ekonomi Program Studi Akuntansi-Univ. Kristen Maranatha \\ (Jl. Prof. Drg. Suria Sumantri No. 65, Bandung) \\ cuynit@yahoo.com \\ Sinta Setiana \\ Fakultas Ekonomi Program Studi Akuntansi-Univ. Kristen Maranatha \\ (Jl. Prof. Drg. Suria Sumantri No. 65, Bandung) \\ sintasetiana73@gmail.com \\ Puput Cintia \\ Fakultas Ekonomi Program Studi Akuntansi-Univ. Kristen Maranatha \\ (Jl. Prof. Drg. Suria Sumantri No. 65, Bandung)
}

\begin{abstract}
The key to success in a change is my source of human being as an initiator and agent of continuous change, the formation of a process and culture that together enhance the ability of organizational change.

Organizational Citizenship Behavior $(O C B)$ is able to increase the effectiveness and success of the organization in the long term. $O C B$ is a positive behavior of people in the organization, which is expressed in the form of willingness to be conscious and voluntary to work beyond the tasks that should be. In the world of work, a person's commitment to an organization or company is often an important issue. The commitment of all individuals in the organization or often referred to as organizational commitment can provide more value to the company in achieving its goals. Organizational effectiveness can also be enhanced by creating a culture that will lead to the achievement of organizational goals (Ismail, 2008). The population in this study is a Private Bank in Bandung. The sample in this study are employees who work in private banks. The statistical method used in this study is multiple regression.

Research results show that organizational commitment influences organizational citizenship behavior, organizational culture influences organizational citizenship behavior and organizational commitment and organizational culture influence organizational citizenship behaviour.
\end{abstract}

Keywords: Organizational Commitment, Organizational Culture, Organizational Citizenship Behaviour 


\section{Pendahuluan}

Sumber daya manusia merupakan bagian hal yang terpenting dalam tercapainya keberhasilan suatu perusahaan, maka perusahaan harus mampu menghadapi berbagai tantangan yang terjadi, karyawan diharapkan mampu menyesuaikan diri dengan perkembangan dan perubahan yang terjadi.

Kunci sukses sebuah perubahan adalah pada sumber daya manusia yaitu sebagai insiator dan agen perubahan terus menerus, pembentukan proses serta budaya yang secara bersama meningkatkan kemampuan perubahan organisasi. Kontribusi karyawan untuk meningkatkan produktivitas perusahaan dibutuhkan dalam meningkatkan kinerja karyawan. Borman dan Motowidlo (dalam Novliadi, 2006) mengatakan bahwa Organizational Citizenship Behaviour dapat meningkatkan kinerja organisasi karena perilaku ini merupakan "pelumas" dari mesin sosial dalam organisasi.

(2006), $\begin{gathered}\text { Menurut Robbins dan Judge } \\ \text { Organizational Citizenship }\end{gathered}$

Behaviour merupakan perilaku pilihan yang tidak menjadi bagian dari kewajiban kerja formal seorang karyawan, namun mendukung berfungsinya organisasi tersebut secara efektif. Organizational Citizenship Behaviour (OCB) mampu meningkatkan efektivitas dan kesuksesan organisasi dalam jangka panjang. OCB merupakan perilaku positif orang-orang yang ada dalam organisasi, yang terekspresikan dalam bentuk kesediaan secara sadar dan sukarela untuk bekerja melebihi tugas yang seharusnya. Munculnya OCB memberikan dampak positif bagi anggota organisasi. Organisasi yang sukses memiliki anggota organisasi yang melampaui tanggung jawab pada pekerjaan formal dan bebas memberikan waktu dan energinya untuk berhasil dalam pekerjaan yang ditugaskan (Rahmi, 2013).

Selain itu, dalam dunia kerja, komitmen seseorang terhadap organisasi atau perusahaan seringkali menjadi isu yang cukup penting. Komitmen semua individu dalam organisasi atau yang sering disebut sebagai komitmen organisasi dapat memberikan nilai (value) yang lebih pada perusahaan dalam mencapai tujuannya. Kredibilitas yang tinggi akan mampu menghasilkan suatu komitmen dan dengan adanya komitmen yang tinggi akan mendukung suatu perusahaan di dalam menghasilkan kinerja yang tinggi (Kouzes, 1993). Komitmen organisasi merupakan pemotivasi untuk semua anggota organisasi untuk perbaikan yang kontinyu atas produk dan jasa sehingga nantinya komitmen organisasi ini dapat memberikan nilai tambah bagi perusahaan dalam mencapai tujuannya (Ellitan \& Anatan, 2007).

Efektivitas organisasi dapat pula ditingkatkan dengan menciptakan budaya yang akan mengarah kepada pencapaian tujuan-tujuan organisasi (Ismail, 2008). Budaya organisasi diperlukan untuk menjadi landasan yang kokoh dalam menjalankan manajemen perusahaan (Widuri dan Paramita,2007). Budaya organisasi merupakan semua bentuk usaha, pikiran dan kegiatan dalam menghadapi, menguasai dan mengendalikan diri dalam organisasi demi kelangsungan organisasi yang bersangkutan (Ismail, 2006).

Berdasarkan latar belakang tersebut, maka peneliti tertarik untuk melakukan penelitian dengan judul: "Pengaruh Komitmen Organisasional dan Budaya Organisasional terhadap Organizational Citizenship Behaviour".

\section{Identifikasi Masalah}

Perumusan permasalahan dalam penellitian ini adalah:

1. Apakah terdapat pengaruh komitmen organisasional terhadap Organizational Citizenship Behaviour?

2. Apakah terdapat pengaruh budaya organisasional terhadap Organizational Citizenship Behaviour?

3. Apakah terdapat pengaruh komitmen organisasional dan budaya 
organisasional terhadap Organizational Citizenship Behaviour?

\section{Tujuan Penelitian}

Berdasarkan perumusan permasalahan yang telah diuraikan sebelumnya, maka tujuan penelitian ini adalah untuk mengetahui:

1. Pengaruh komitmen organisasional terhadap Organizational Citizenship Behaviour.

2. Pengaruh budaya organisasional terhadap Organizational Citizenship Behaviour.

3. Pengaruh komitmen organisasional dan budaya organisasional terhadap Organizational Citizenship Behaviour.

\section{Kerangka Teoritis dan Hipotesis}

\section{Kerangka Teoritis \\ Komitmen Organisasi}

Fullerton (2003) mendefinisikan komitmen sebagai berikut :

"Commitment is an agreement to do something for yourself, another individual, group, or organization. Commitment is a force that binds an individual to a course of action of relevance to one or more targets".

Komitmen organisasional merupakan pengenalan dan loyalitas seseorang terhadap sebuah organisasi. (Good et al 1996). Komitmen terhadap suatu organisasi meliputi sikap (attitude) :
a) Rasa (sense) pengenalan terhadap tujuan organisasi
b) Rasa (feeling) keterlibatan dalam tugas-tugas organisasional.
c) Rasa (feeling) loyalitas terhadap organisasi. (Ivancevich dan Matteson 1999 : 25)

\section{Jenis-Jenis Komitmen Organisasi}

Pakar komitmen Mayer dan Allen, mendefinisikan empat jenis komitmen organisasi, yaitu :

\section{Komitmen Affective}

Menurut Allen dan Meyer (1990), komitmen affective didasarkan pada emotional attachment (keterikatan emosional) individu terhadap organisasi. Individu yang memiliki komitmen affective yang kuat akan mengidentifikasi, dilibatkan, dan menikmati keanggotaannya dalam organisasi.

\section{Komitmen Continuance}

Komitmen ini didasarkan pada perceived cost (Allen dan Meyer, 1990) maksudnya adalah individu yang memiliki komitmen continuance didasarkan pada pertimbangan tentang apa yang harus dikorbankan jika individu tersebut meninggalkan organisasi.

\section{Komitmen Normative}

Dalam konteks perilaku organisasional, sense of moral obligation seseorang terhadap organisasi merupakan inti komitmen normative (Alen dan Meyer, 1990). Perasaan obligation (kewajiban) tetap loyal berasal dari internalisasi tekanan-tekanan normatif.

\section{Budaya Organisasi}

Menurut Lako (2004), budaya organisasi adalah pola keyakinan dan nilai-nilai yang ada di dalam organisasi yang dipahami, dijiwai dan dipraktekkan oleh organisasi sehingga pola tersebut memberikan arti tersendiri dan menjadi dasar aturan berperilaku dalam organisasi.

Hal serupa seperti yang didefinisikan oleh Tampubolon (2004) bahwa budaya organisasi adalah perekat sosial yang mengikat anggota-anggota organisasi secara bersama-sama melalui nilai-nilai, normanorma standar yang jelas tentang apa yang dapat dan tidak dapat dilakukan oleh anggotanya.

Dari berbagai definisi budaya organisasi yang telah dikemukakan, dapat ditarik simpulan bahwa budaya organisasi adalah sistem nilai yang diyakini oleh semua anggota perusahaan dan yang dipelajari, diterapkan serta dikembangkan 
secara berkesinambungan, berfungsi sebagai sistem perekat dan dapat dijadikan acuan berperilaku dalam perusahaan untuk mencapai tujuan perusahaan yang telah ditetapkan.

\section{Fungsi Budaya Organisasi}

Konsultan Manajemen McKinsey \& Co dalam Lowney (2005) melakukan riset terhadap para karyawan pada salah satu perusahaan besar mengenai apa yang memotivasi para karyawan di dalam di perusahaan tersebut. Berikut ini adalah ringkasan mengenai peringkat faktor yang mutlak essensial untuk memotivasi karyawan berbakat :

Tabel 1

\section{Peringkat Faktor Untuk Memotivasi Karyawan}

\begin{tabular}{|l|l|}
\hline Nilai-Nilai Budaya & $58 \%$ \\
\hline Kebebasan Otonomi & $56 \%$ \\
\hline Tugas Mengandung Tantangan & $51 \%$ \\
\hline Pengelolaan yang baik & $50 \%$ \\
\hline Kompensansi yang tinggi & $23 \%$ \\
\hline Misi yang mengilhami & $16 \%$ \\
\hline
\end{tabular}

Hasil riset menunjukkan bahwa nilai dalam budaya organisasi sangat mempengaruhi motivasi para anggota dalam bekerja. Supaya seseorang dapat menjalankan fungsinya secara efektif dalam suatu organisasi, seseorang perlu tahu bagaimana mengerjakan atau harus mengerjakan sesuatu, termasuk bagaimana berperilaku sebagai anggota organisasi, khususnya dalam lingkungan organisasinya. (Widuri dan Paramita, 2007).

\section{Karakteristik Budaya Organisasi}

Karakteristik budaya organisasi menurut Robbins dan Coulter tersebut kemudian diterjemahkan kembali oleh Tika (2006) sebagai berikut:

1. Perhatian Pada Detail, yaitu sejauhmana karyawan diharapkan mampu menunjukkan ketepatan, analisis dan perhatian pada setiap detail pekerjaan mereka.
2. Orientasi Hasil, yaitu sejauhmana manajer berfokus kepada hasil yang dapat dicapai oleh perusahaan.

3. Orientasi Orang, yaitu sejauhmana keputusan manajemen turut mempengaruhi orang-orang yang ada di dalam perusahaan tersebut.

4. Orientasi Tim, yaitu sejauhmana suatu organisasi dapat mendorong unit-unit di dalam organisasi tersebut bekerja dengan cara terkoordinasi atau pekerjaan dilakukan berdasarkan pada tim bukan secara perorangan.

5. Keagresifan, Inovasi dan Pengambilan Risiko, yaitu sejauhmana pegawai dianjurkan untuk dapat bertindak agresif di dalam melakukan pekerjaannya, inovatif dan berani mengambil risiko dalam mengambil keputusan yang dapat memajukan dan mengembangkan organisasi.

6. Stabilitas, yaitu sejauhmana keputusan yang diambil dan tindakan yang dilakukan oleh perusahaan, tetap dapat mempertahankan atau memegang teguh norma atau aturan yang berlaku yang ada di dalam perusahaan, sehingga keberadaan "status quo" perusahaan dapat tetap terjaga.

\section{Organizational Citizenship Behavior}

Robbins dan Judge (2008) mendefinisikan OCB sebagai perilaku pilihan yang tidak menjadi bagian dari kewajiban kerja formal seorang karyawan, namun mendukung berfungsinya organisasi tersebut secara efektif. Shweta dan Srirang (2009) dalam Rahmi (2013), menyatakan bahwa OCB ditandai dengan usaha dalam bentuk apapun yang dilakukan berdasarkan kebijaksanaan pegawai yang memberikan manfaat bagi organisasi tanpa mengharapkan imbalan apapun.

\section{Komponen Organizational Citizenship Behaviour \\ Komponen OCB menurut Konovsky dan Organ (1996); Jahangir et al. (2004);}


Organ et al. (2006); DiPaoladan Neves (2009); Ahmed et al. (2012), Chiang dan Hsieh(2012) dalam Rahmi (2013:38-40), yaitu:

\section{Altruism}

Altruism adalah perilaku berinisiatif untuk membantu atau menolong rekan kerja dalam organisasi secara sukarela.

2. Courtesy

Courtesy adalah perilaku individu yang menjaga hubungan baik dengan rekan kerjanya agar terhindar dari perselisihan antar anggota dalam organisasi.

3. Sportsmanship

Sportsmanship adalah kesediaan individu menerima apapun yang ditetapkan oleh organisasi meskipun dalam keadaan yang tidak sewajarnya.

4. Conscientiousness

Conscientiousness adalah pengabdian atau dedikasi yang tinggi pada pekerjaan dan keinginan untuk melebihi standar pencapaian dalam setiap aspek.

5. Civic Virtue

Civic virtue adalah perilaku individu yang menunjukkan bahwa individu tersebut memiliki tanggung jawab untuk terlibat, berpartisipasi, turut serta, dan peduli dalam berbagai kegiatan yang diselenggarakan organisasi.

\section{Hipotesis}

Perumusan hipotesis dalam penelitian ini terbagi dalam 3 bagian sebagai berikut:

$\mathrm{H}_{1}=$ Terdapat pengaruh parsial Komitmen Organisasional terhadap Organizational Citizenship Behaviour

$\mathrm{H}_{2}=$ Terdapat pengaruh parsial Budaya Organisasional terhadap Organizational Citizenship Behaviour

$\mathrm{H}_{3}=$ Terdapat pengaruh simultan Komitmen Organisasional dan Budaya Organisasional terhadap Organizational Citizenship Behaviour

\section{Metode Penelitian}

\section{Populasi dan Sampel}

Populasi adalah wilayah generalisasi yang terdiri atas objek atau subjek yang mempunyai kualitas dan karakterisktik tertentu yang ditetapkan oleh peneliti untuk dipelajari dan kemudian ditarik kesimpulan (Sugiyono, 2011). Populasi adalah keseluruhan objek yang karakteristiknya akan diuji (Suliyanto, 2006). Populasi dalam penelitian ini adalah karyawan Bank BCA Asia Afrika dan Soekarno Hatta dan Bank Panin Asia Afrika ada di Bandung.

Sampel adalah bagian dari jumlah dan karakteristik yang dimiliki oleh populasi tersebut (Sugiyono, 2011). Sampel yang baik adalah sampel yang benar-benar dapat digunakan untuk menggambarkan karakteristik populasinya (Suliyanto, 2006). Teknik pengambilan sampel yang digunakan adalah random sampling dimana setiap unit dalam populasi mempunyai kesempatan yang sama untuk dipilih menjadi anggota sampel. Sampel yang terkumpul dalam penelitian ini berjumlah 70 kuesioner.

\section{Operasionalisasi Variabel}

\begin{tabular}{|c|c|c|c|}
\hline Variabel & Dimensi & Indikator & Skala \\
\hline $\begin{array}{l}\text { Komitmen } \\
\text { Organisasi } \\
\text { onal (X1) }\end{array}$ & $\begin{array}{l}\text { Komitmen } \\
\text { Afektif } \\
\text { Komitmen } \\
\text { Continuence } \\
\\
\text { Komitmen } \\
\text { Normatif }\end{array}$ & $\begin{array}{l}\text { Emosional/ } \\
\text { keinginan } \\
\text { dari dalam } \\
\text { hati. } \\
\text { Pemenuhan } \\
\text { akan } \\
\text { kebutuhan. } \\
\text { Kewajiban } \\
\text { Sumber: } \\
\text { Allen and } \\
\text { Mayer } \\
\text { (1990) }\end{array}$ & Interval \\
\hline $\begin{array}{l}\text { Budaya } \\
\text { Organisasi } \\
\text { onal (X2) }\end{array}$ & $\begin{array}{l}\text { Attention } \\
\text { Detail }\end{array}$ & $\begin{array}{l}\text { Ketepatan, } \\
\text { analisis dan } \\
\text { perhatian } \\
\text { pada detail } \\
\text { pekerjaan } \\
\text { dari } \\
\text { karyawan. }\end{array}$ & Interval \\
\hline
\end{tabular}




\begin{tabular}{|c|c|c|c|}
\hline & $\begin{array}{l}\text { Outcome } \\
\text { Orientation } \\
\text { People } \\
\text { Orientation } \\
\\
\\
\text { Team } \\
\text { Orientation } \\
\\
\text { Aggresivene } \\
\text { ss, Inovation } \\
\text { dan Risk } \\
\text { Tasking }\end{array}$ & $\begin{array}{l}\text { Fokus pada } \\
\text { hasil } \\
\text { perusahaan } \\
\text { Keputusan } \\
\text { manajemen } \\
\text { yang } \\
\text { memengaru } \\
\text { hi orang- } \\
\text { orang } \\
\text { dalam } \\
\text { perusahaan. } \\
\text { Pekerjaan } \\
\text { dilakukan } \\
\text { berdasarkan } \\
\text { tim/kelomp } \\
\text { ok } \\
\text { Karyawan } \\
\text { yang } \\
\text { dituntut } \\
\text { untuk } \\
\text { agresif, } \\
\text { inovasi dan } \\
\text { berani } \\
\text { mengambil } \\
\text { resiko. } \\
\text { Keputusan } \\
\text { dan } \\
\text { tindakan } \\
\text { organisasi } \\
\text { tetap } \\
\text { memegang } \\
\text { norma atau } \\
\text { aturan } \\
\text { untuk } \\
\text { mempertah } \\
\text { ankan } \\
\text { status quo } \\
\text { Sumber : } \\
\text { Robbins } \\
\text { and } \\
\text { Coulter } \\
\text { (2007) }\end{array}$ & \\
\hline $\begin{array}{l}\text { Organizat } \\
\text { ional } \\
\text { Citizenshi } \\
p \\
\text { Behaviour } \\
(\mathrm{X} 3)\end{array}$ & $\begin{array}{l}\text { Alturism } \\
\text { Courtessy }\end{array}$ & $\begin{array}{l}\text { Perilaku } \\
\text { inisiatif } \\
\text { untuk } \\
\text { membantu } \\
\text { dan } \\
\text { menolong } \\
\text { sesama } \\
\text { rekan kerja. } \\
\text { Perilaku } \\
\text { untuk } \\
\text { menjaga } \\
\text { hubungan }\end{array}$ & Interval \\
\hline
\end{tabular}

204

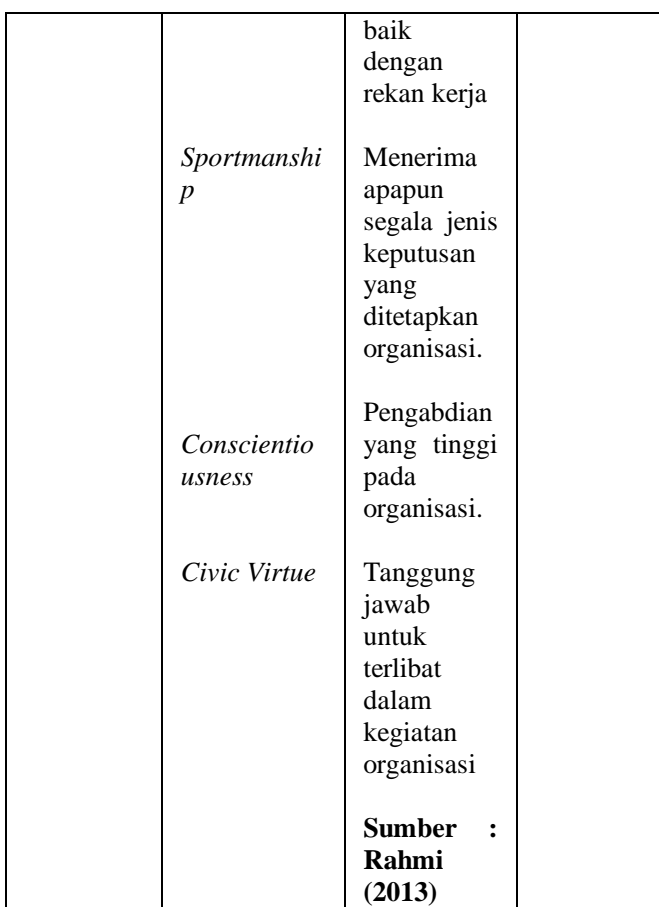

\section{Teknik Pengujian Data}

\section{Validitas dan Reliabilitas}

Validitas merupakan suatu ukuran yang menunjukkan tingkat keandalan atau keabsahan suatu alat ukur. Informasi validitas menunjukkan tingkat dari kemampuan tes untuk mencapai sasarannya (Isaac dan Michael dalam Hartono, 2011). Validitas berhubungan dengan ketepatan alat ukur untuk melakukan tugasnya mencapai sasarannya (Hartono, 2011).

Keputusan bahwa butir-butir pertanyaan dianggap valid dapat dilakukan dengan cara sebagai berikut:

Jika koefisien korelasi product moment melebihi 0,3 (Azwar dalam Sugiyono dalam Sunjoyo dkk., 2013).

Jika koefisien korelasi product moment> $\mathrm{r}$ tabel $(\alpha ; n-2) n=$ jumlah sampel

Nilai sig $\leq \alpha$

(Suliyanto dalam Sunjoyo dkk., 2013).

Dalam penelitian ini, uji validitasnya menggunakan metode pearson yang dilakukan dengan membandingkan antara $r$ hitung dengan $r$ tabelnya. Jika $r$ hitung lebih besar dari $r$ tabel dan nilainya 
positif, maka pernyataan tersebut dapat dikatakan valid.

$$
\text { Realibilitas merupakan sejauh }
$$

mana hasil suatu pengukuran dapat dipercaya (Suliyanto, 2006). Reliabilitas berhubungan dengan akurasi dari pengukuran. Suatu pengukur dikatakan reliabel jika dapat dipercaya (Hartono, 2011).

Pengukuran reliabilitas dilakukan dengan dua cara, yaitu:

\section{Repeat Measure}

Seseorang akan disodori pertanyaan yang sama pada waktu yang berbeda dan kemudian dilihat apakah jawabannya konsisten atau tidak.

One shot

Pengukuran hanya sekali dan hasilnya dibandingkan dengan pertanyaan lain. Ada suatu nilai ketentuan untuk mengukur reliabilitas dengan uji statistic Cronbach Alpha $(\alpha)$. Suatu konstruk dikatakan reliabel jika memiliki Cronbach Alpha> 0,700. (Ghozali dalam Nunnally dalam Agustina dan Yoestini, 2012).

\section{Uji Asumsi Klasik}

Uji asumsi klasik adalah persyaratan statistik yang harus dipenuhi pada analisis regresi linear yang berbasis Ordinary Least Square (Priyanto, 2008). Asumsi ini dikembangkan oleh Carl Fredrich pada tahun 1821 dan dikatakan bahwa model regresi disebut baik jika memenuhi 3 asumsi, yaitu: Multikolinieritas, Heteroskedastisitas, dan Autokorelasi. Sebelum dilaksanakan uji asumsi klasik, diperlukan uji normalitas.

\section{Uji Normalitas}

Uji normalitas adalah pengujian untuk melihat apakah data tersebut normal atau tidak. Model regresi yang baik adalah memiliki nilai residual terdistribusi normal (Sunjoyo dkk., 2013). Uji normalitas dapat dilakukan dengan uji histogram, uji normal P Plot, uji Chi Square, Skewness dan Kurtosis atau uji Kolmogorov Smirnov (Sunjoyo dkk., 2013).

\section{Uji Multikolinearitas}

Uji multikolinearitas adalah untuk melihat ada atau tidaknya korelasi yang tinggi antara variabel-variabel bebas dalam suatu model regresi linear berganda. Jika ada korelasi yang tinggi di antara variabelvariabel bebasnya, maka hubungan antara variabel bebas terhadap variabel terikatnya menjadi terganggu (Sunjoyo dkk., 2013).

Alat statistik yang sering dipergunakan untuk menguji gangguan multikolinearitas adalah:

Jika nilai VIF tidak lebih dari 10 dan nilai Tolerance tidak kurang 0,1 , maka model dapat dikatakan terbebas dari multikolinearitas, VIF $=1 /$ Tolerance, jika $\mathrm{VIF}=10$, maka Tolerance $1 / 10=0,1$. Semakin tinggi VIF maka semakin rendah Tolerance.

Jika nilai koefisien korelasi antar masing-masing variabel independen kurang dari 0,70 , maka model dapat dinyatakan bebas dari multikolinearitas. Jika nilai korelasi lebih dari 0,70 , berarti terjadi korelasi yang sangat kuat antar variabel independen sehingga terjadi multikolinearitas.

Jika nilai koefisien determinan, baik $\mathrm{R}^{2}$ ataupun Adjusted $R^{2}$ di atas 0,60 namun tidak ada variabel independen yang berpengaruh terhadap variabel dependen, maka diasumsikan model terkenal multikolinearitas. (Nugroho dalam Sunjoyo dkk., 2013).

\section{Uji Heteroskedastisitas}

Uji Heterokedastisitas adalah untuk melihat apakah terdapat ketidaksamaan varians dari residual satu pengamatan ke pengamatan yang lain. Model regresi yang memenuhi persyaratan adalah dimana terdapat kesamaan varians dari residual satu pengamatan ke pengamatan yang lain tetap. Uji statistik yang dapat digunakan adalah uji Glejser, uji Spearman Rho, uji Park, atau uji White. Untuk pengujian ini digunakan uji Spearman Rho. 


\section{Uji Multiple Regression Analysis}

Metode statistik yang digunakan dalam penelitian ini adalah regresi berganda. Metode ini mengestimasi besarnya koefisien-koefisien yang dihasilkan dari persamaan yang bersifat linier yang melibatkan dua variabel bebas atau lebih sebagai alat prediksi besarnya variabel terikat (Rochaety et.al, 2007:131). Sesuai dengan hipotesis yang diuji dalam penelitian ini maka persamaan regresi berganda adalah sebagai berikut: $\mathrm{Y}=\beta_{0}+$ $\beta_{1} X+\beta_{2} X_{2}+\beta_{3} X_{1} X_{2}+\varepsilon$

\section{Hasil Penelitian dan Pembahasan}

\section{Gambaran Umum Objek Penelitian}

Objek penelitian pada penelitian ini adalah Bank BCA Asia Afrika dan Soekarno Hatta dan Bank Panin Asia Afrika. Responden dalam penelitian ini adalah karyawan Bank BCA Asia Afrika dan Soekarno Hatta dan Bank Panin Asia Afrika.

\section{Hasil penelitian \\ Uji Instrumen Penelitian \\ Uji Validitas}

Validitas merupakan suatu ukuran yang menunjukan tingkat keandalan atau keabsahan suatu alat ukur. Validitas merupakan derajat ketepatan antara data yang terjadi pada objek penelitian dengan data yang dilaporkan oleh peneliti (Sugiyono, 2014).

Dalam penelitian ini, uji validitasnya menggunakan metode pearson yang dilakukan dengan membandingkan antara $r$ hitung dengan $r$ tabelnya. Jika $r$ hitung lebih besar dari $r$ tabel dan nilainya positif, maka pernyataan tersebut dapat dikatakan valid.

Hasil Uji validitas semua dimensi variabel $\mathrm{X} 1, \mathrm{X} 2$ dan $\mathrm{Y}$ dinyatakan valid dikarenakan nilai butirnya lebih besar dari 0.3 .

\section{Uji Reliabilitas}

Reliabilitas merupakan sejauh mana hasil suatu pengukuran dapat dipercaya
(Suliyanto, 2006). Reliabilitas berhubungan dengan akurasi dari pengukuran. Suatu pengukur dikatakan reliabel jika dapat dipercaya (Hartono, 2011). Pengukuran reliabilitas dalam penelitian ini dilakukan dengan menggunakan koefisien cronbach alpha $(\alpha)$ dengan menggunakan SPSS. Suatu konstruk dikatakan reliabel jika memiliki Cronbach Alpha > 0,7. (Ghozali dalam Nunnally dalam Agustina dan Yoestini, 2012).

Hasil uji Reliabilitas variabel X1, X2 dan Y menunjukkan nilai cronbach alpha lebih dari 0.7 sehingga data-data yang digunakan dalam penelitian ini adalah reliabel.

\section{Uji Asumsi Klasik}

\section{Uji Normalitas}

Uji normalitas adalah pengujian untuk melihat apakah data tersebut normal atau tidak. Model regresi yang baik adalah memiliki nilai residual terdistribusi normal (Sunjoyo dkk., 2013). Uji normalitas dalam penelitian ini adalah menggunakan Uji Kolmogorov Smirnov. Jika nilai signifikan $\leq 0.05$ maka distribusi data tidak normal, jika nilai signifikan $\geq 0.05$ maka distribusi data normal.

Berdasarkan tabel 2 di bawah ini, data tidak berdistribusi normal, karena nilai nya kurang dari sig ( 0.05) menurut perhitungan Kolmogorov Smirnov dengan menggunakan SPSS versi 23. 
Tabel 2

Hasil Uji Normalitas

\begin{tabular}{|ll|l|} 
One-Sample Kolmogorov-Smirnov Test \\
\hline \multirow{2}{*}{\begin{tabular}{ll|} 
N \\
Normal Parameters ${ }^{\mathrm{a}, \mathrm{b}}$
\end{tabular}} & $\begin{array}{l}\text { Unstandardized } \\
\text { Residual }\end{array}$ \\
\hline \multirow{3}{*}{ Most Extreme Differences } & Mean & 117 \\
& Std. Deviation & .0000000 \\
\cline { 2 - 3 } & Absolute & .26116644 \\
\cline { 2 - 3 } & Positive & .064 \\
\hline Test Statistic & Negative & -.038 \\
\hline Asymp. Sig. (2-tailed) & & .064 \\
\hline
\end{tabular}

Test distribution is Normal

b. Calculated from data.

c. Lilliefors Significance Correction.

d. This is a lower bound of the true significance.

Berdasarkan data tabel 2 di atas didapat nilai Asymp.sig 0.200, dengan kata lain nilai tersebut lebih besar dari nilai alpha 0.05. Maka data pada penelitian ini dinyatakan normal.

\section{Uji Multikolinearitas}

Uji multikolinearitas adalah untuk melihat ada atau tidaknya korelasi yang tinggi antara variabel-variabel bebas dalam suatu model regresi linear berganda. Alat statistik yang digunakan dalam penelitian ini mengacu pada nila VIF (Variance Inflation Factor). Jika nilai VIF tidak lebih dari 10 dan nilai Tolerance tidak kurang 0,1 , maka model dapat dikatakan terbebas dari multikolinearitas, VIF $=1 /$ Tolerance, jika $\mathrm{VIF}=10$, maka Tolerance $1 / 10=0,1$. Semakin tinggi VIF maka semakin rendah Tolerance.
Tabel 3

Hasil Uji Multikolinearitas

Coefficients $^{\mathrm{a}}$

\begin{tabular}{|c|c|c|c|c|c|c|c|}
\hline \multirow[b]{2}{*}{ Model } & \multicolumn{2}{|c|}{$\begin{array}{l}\text { Unstandardize } \\
\text { d Coefficients }\end{array}$} & \multirow{2}{*}{$\begin{array}{c}\begin{array}{c}\text { Standard } \\
\text { ized } \\
\text { Coeffici } \\
\text { ents }\end{array} \\
\text { Beta }\end{array}$} & \multirow[b]{2}{*}{$\mathrm{T}$} & \multirow[b]{2}{*}{ Sig. } & \multicolumn{2}{|c|}{$\begin{array}{c}\text { Collinearity } \\
\text { Statistics }\end{array}$} \\
\hline & B & $\begin{array}{l}\text { Std. } \\
\text { Error }\end{array}$ & & & & $\begin{array}{c}\text { Toler } \\
\text { ance }\end{array}$ & VIF \\
\hline $\begin{array}{l}1 \text { (Con } \\
\text { stant) }\end{array}$ & 1.024 & .178 & & 5.740 & .000 & & \\
\hline $\begin{array}{c}\text { Total } \\
\text { X1 }\end{array}$ & .204 & .054 & .249 & 3.801 & .000 & .570 & 1.755 \\
\hline $\begin{array}{c}\text { Total } \\
\text { X2 }\end{array}$ & .562 & .055 & .664 & $\begin{array}{r}10.13 \\
4\end{array}$ & .000 & .570 & 1.755 \\
\hline
\end{tabular}

Berdasarkan tabel 3 di atas, menunjukkan bahwa nilai tolerance tidak kurang dari 0.1 dan nilai VIF tidak lebih dari 10, maka data data yang dipakai dalam penelitian ini sudah terbebas dari multikolinearitas atau tidak terdapat masalah multikolinearitas.

\section{Uji Heterokedastisitas}

Uji Heterokedastisitas adalah untuk melihat apakah terdapat ketidaksamaan varians dari residual satu pengamatan ke pengamatan yang lain. Model regresi yang memenuhi persyaratan adalah dimana terdapat kesamaan varians dari residual satu pengamatan ke pengamatan yang lain tetap. Cara untuk melihat ada tidaknya heterokedastisitas salah satunya menggunakan grafik plot antara nilai prediksi variabel terkait dengan nilai residualnya. Deteksi ada tidaknya heterokedastisitas dapat dilakukan dengan melihat ada tidaknya pola tertentu pada grafik antara sumbu y (prediksi) dengan sumbu x ( residual)

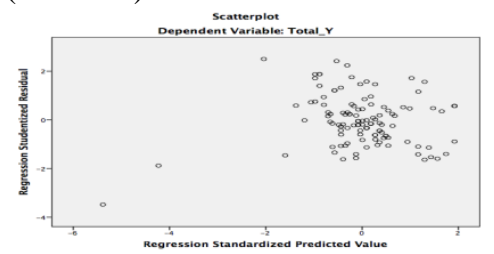

Gambar 1

Scatter Plot 
Berdasarkan gambar di atas menunjukkan tidak adanya pola tertentu pada grafik scatterplot antara variable dependent dengan independent, maka dapat disimpulkan bawah data terbebas atau tidak mengandung unsur heterokedastisitas.

\section{Hasil Uji Hipotesis}

Pengujian hipotesis dalam penelitian ini menggunakan model Multiple Regression Analysis. Metode ini mengestimasi besarnya koefisien-koefisien yang dihasilkan dari persamaan yang bersifat linier yang melibatkan dua variabel bebas atau lebih sebagai alat prediksi besarnya variabel terikat (Rochaety et.al, 2007:131).

Uji Pengaruh ( Koefisien Determinasi)

a. Untuk melihat pengaruh masingmasing dimensi terhadap dimensi Y, maka dapat dilihat dari nilai pearson corelationnya (r) yang berasal dari tabel correlation

Tabel 4

Uji Korelasi Determinan Coefficients $^{\mathrm{a}}$

\begin{tabular}{|ll|r|r|r|}
\hline & & Total_Y & Total_X1 & Total_X2 \\
\hline Pearson & Total_Y & 1.000 & .685 & .828 \\
Correlation & Total_X1 & .685 & 1.000 & .656 \\
& Total_X2 & .828 & .656 & 1.000 \\
\hline \multirow{2}{*}{ Sig. (1-tailed) } & Total_Y &. & .000 & .000 \\
\cline { 2 - 5 } & Total_X1 & .000 &. & .000 \\
& Total_X2 & .000 & .000 &. \\
\hline N & Total_Y & 117 & 117 & 117 \\
& Total_X1 & 117 & 117 & 117 \\
& Total_X2 & 117 & 117 & 117 \\
\hline
\end{tabular}

Keterangan :

1. Untuk mengetahui besar pengaruh dimensi $\mathrm{X} 1$ terhadap $\mathrm{Y}$ di dapat nilai korelasi ( $\mathrm{r}$ ) adalah 0.685. Dengan menggunakan rumus $\mathrm{KD}$ ( Koefisien determinasi) maka di dapat hasil besar pengaruh dimensi $\mathrm{X} 1$ terhadap $\mathrm{Y}$ adalah $46.93 \%(46.9225)$.

2. Untuk mengetahui besar pengaruh dimensi $\mathrm{X} 2$ terhadap $\mathrm{Y}$ di dapat nilai korelasi ( $\mathrm{r}$ ) adalah 0.828. Dengan menggunakan rumus $\mathrm{KD}$ ( Koefisien determinasi) maka di dapat hasil besar pengaruh dimensi $\mathrm{X} 1$ terhadap $\mathrm{Y}$ adalah $68.56 \%$ (68.5584) .

b. Uji Pengaruh secara bersamaan dapat dilihat dari tabel model summary.

Tabel 5

Uji Korelasi Secara Bersamaan

\begin{tabular}{|l|c|r|r|c|}
\hline Model Summary \\
\hline Model & $\mathrm{R}$ & $\begin{array}{c}\mathrm{R} \\
\text { Square }\end{array}$ & $\begin{array}{c}\text { Adjusted } \\
\text { R Square }\end{array}$ & $\begin{array}{c}\text { Std. Error of the } \\
\text { Estimate }\end{array}$ \\
\hline 1 & $.849^{\mathrm{a}}$ & .721 & .716 & .26345 \\
\hline
\end{tabular}

Untuk mengetahui besar pengaruh dimensi $\mathrm{X} 1$ dan X2 secara bersama-sama terhadap dimensi Y adalah 0.716 atau $\mathbf{7 1 . 6 \%}$.

\section{Uji Hipotesis.}

Untuk mengetahui apakah $\mathrm{Ho}$ atau $\mathrm{H} 1$ diterima, dengan menggunakan tabel Anova kita dapat melihat apakah hipotesis penelitian dapat diterima atau tidak. Dengan tabel anova juga kita dapat melihat pengaruh secara bersama - sama.

Tabel 6

Uji Hipotesis ANOVA $^{\mathrm{a}}$

\begin{tabular}{|c|c|c|c|c|c|c|}
\hline Model & & $\begin{array}{l}\text { Sum of } \\
\text { Squares }\end{array}$ & df & $\begin{array}{l}\text { Mean } \\
\text { Square }\end{array}$ & $\mathrm{F}$ & Sig. \\
\hline \multirow[t]{3}{*}{1} & Regression & 20.421 & 2 & 10.211 & 147.116 & $.000^{\mathrm{b}}$ \\
\hline & Residual & 7.912 & 114 & .069 & & \\
\hline & Total & 28.333 & 116 & & & \\
\hline
\end{tabular}

a. Dependent Variable: Total_Y

b. Predictors: (Constant), Total_X2, Total_X1

Tabel 7

Uji Hipotesis Secara Parsial. Coefficients $^{\mathrm{a}}$

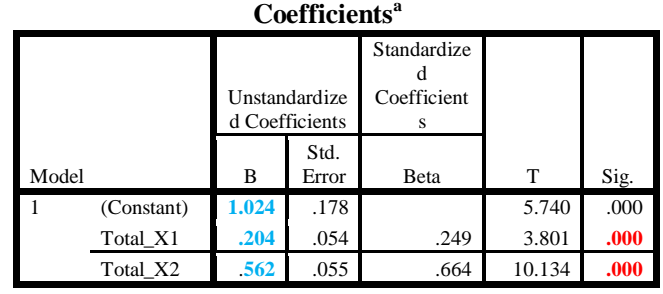

a. Dependent Variable: Total_Y 
Berdasarkan tabel 7 diatas, maka dapat persamaan regresi :

$$
\begin{aligned}
& Y=1.024+0.204 X 1+0.562 X 2 \\
& Y=\beta_{0}+\beta_{1} X+\beta_{2} X_{2}+\beta_{3} X_{1} X_{2}+\varepsilon
\end{aligned}
$$

Pengujian hipotesis Pengaruh Komitmen Organisasional terhadap Organizational Citizenship Behaviour.

Berdasarkan hasil pengujian diatas, menunjukkan bahwa komitmen organisasional berpengaruh terhadap organizational citizenship behavior. Konfirmasi terhadap pengujian ini dilakukan dengan melihat hasil uji statistic, dengan tingkat probabilitas (sig.) t variabel komitmen organisasi sebesar 0.00 lebih kecil dari 0.05 dengan koefisien 0,204. Hal ini menunjukkan bahwa $\mathrm{H}_{1}$ diterima, dengan kesimpulan Komitmen Organisasional berpengaruh terhadap Organizational Citizenship Behaviour.

Karyawan memiliki kredibilitas yang baik sehingga terbentuk komitmen yang tinggi pada perusahaan. Dengan adanya komitmen yang tinggi ini, maka karyawan memiliki keinginan yang tinggi juga untuk mendukung perusahaan mencapai tujuannya dan membantu merealisasikan tujuan perusahaan tersebut. Mereka akan berperilaku positif, bersedia secara sadar dan sukarela untuk bekerja sesuai bahkan melebihi tugasnya, sehingga semuanya itu mampu meningkatkan efektivitas dan kesuksesan organisasi.

Pengujian hipotesis Pengaruh Budaya Organisasi terhadap Organizational Citizenship Behaviour.

Berdasarkan hasil pengujian diatas, menunjukkan bahwa budaya organisasi berpengaruh terhadap organizational citizenship behavior. Konfirmasi terhadap pengujian ini dilakukan dengan melihat hasil uji statistik, dengan tingkat probabilitas (sig.) $\mathrm{t}$ variabel budaya organisasi sebesar 0.00 lebih kecil dari 0.05 dengan koefisien 0,562 . Hal ini menunjukkan bahwa $\mathrm{H}_{2}$ diterima, dengan kesimpulan Budaya Organisasi berpengaruh terhadap Organizational Citizenship Behaviour.

Budaya Organisasi yang baik dalam perusahaan dapat menjadi landasan yang kokoh dan kuat dalam menjalani manajemen perusahaan. Budaya organisasi yang baik ini membentuk perilaku, pikiran dan pekerjaan (kegiatan) yang dilakukan oleh karyawan dalam menghadapi dan mengendalikan diri dalam melakukan pekerjaannya dalam organisasi. Budaya organisasi yang baik ini dapat meningkatkan efektivitas penerapan OCB dalam perusahaan.

\section{Pengujian hipotesis Pengaruh Komitmen Organisasional dan Budaya Organisasi terhadap Organizational Citizenship Behaviour.}

Berdasarkan hasil pengujian di atas, menunjukkan bahwa komitmen organisasi dan budaya organisasi berpengaruh terhadap organizational citizenship behaviour. Konfirmasi terhadap pengujian ini dilakukan dengan melihat hasil uji statistik, berdasarkan tabel 6 didapatkan nilai sig adalah $\mathbf{0 . 0 0}$ dengan kata lain nilai sig lebih kecil dari nilai alpha $\mathbf{0 . 0 5}$. Hal ini menunjukkan bahwa $\mathrm{H}_{3}$ diterima, dengan kesimpulan Komitmen Organisasi dan Budaya Organisasi secara bersama-sama (simultan) berpengaruh terhadap Organizational Citizenship Behaviour.

Organisasi yang baik dapat membantu dan mendukung karyawannya untuk melakukan aktualisasi diri, sehingga akan tumbuh komitmen yang baik dari para karyawannya tersebut. Selain itu, dengan didukung oleh budaya yang baik dalam organisasi tersebut, dapat membentuk perilaku karyawan menjadi lebih baik, bertanggung jawab dalam segala hal (baik itu pekerjaannya sendiri maupun bukan), dapat membantu organisasi tersebut untuk meningkatkan efektivitas Organizational Citizenship behaviour dalam organisasi tersebut. 


\section{Simpulan dan Saran}

\section{Simpulan}

1. Berdasarkan hasil penelitian, menunjukkan bahwa komitmen organisasional berpengaruh terhadap organizational citizenship behavior.

2. Berdasarkan hasil penelitian, menunjukkan bahwa budaya organisasi berpengaruh terhadap organizational citizenship behavior.

3. Berdasarkan hasil penelitian menunjukkan bahwa komitmen organisasi dan budaya organisasi berpengaruh terhadap organizational citizenship behavio

\section{Saran}

1. Penelitian ini dilakukan pada bank yang berada di Kota Bandung, disarankan penelitian selanjutnya dapat meneliti seluruh bank dengan wilayah lebih luas atau bidang usaha lainnya dalam cakupan skala besar, sedang maupun kecil.

2. Variabel disarankan untuk diteliti seperti kepuasan kerja, kepemimpinan atau lainnya yang dapat mempengaruhi OCB.

\section{Daftar Pustaka}

Allen, Natalie J. and John P.Meyer. 1990. The Measurement and Antecedents of Affective, Continuance and Normative Commitment to The Organization. Journal of Occupational Phychology. Vol 63.

Agustina, Vina Yoestini, "Analisis Pengaruh Kualitas Pelayanan, Kepuasan Pelanggan, dan Nilai Pelanggan dalam Meningkatkan Loyalitas Pelanggan Joglosemar Bus (Studi pada Wilayah Semarang Town Office)". Diponegoro Journal
Of Management. Volume 1, Nomor 1, Tahun 2012, Halaman 1-11.

Bendapudi, N. and L. Berry. 1997. Customers' Motivations for Maintaining Relationships with Service Providers. Journal of Retailing. Vol 37.

Ellitan,Lena dan Anatan,Lina. 2007. Manajemen Operasi dalam Era Baru Manufaktur. Edisi I. Bandung: Alphabeta.

Fullerton, G. 2003. When Does Commitment Lead to Loyalty? Journal of Service Research, Vol 5. Pp. 333-344.

Good, L. K., Page, T. J., \& Young, C. E. 1996. Assesing hierarchical differences in job-related attitudes and turnover among retail managers. Journal of Academy of Marketing Science.

Hartono. 2011. Metodologi Penelitian. Zanafa Publishing. Pekanbaru

Ismail, Irani. 2008. Pengaruh Budaya Organisasi Terhadap Kepemimpinan dan Kinerja Karyawan Pemerintah Kabupaten - Kabupaten di Madura. Ekuitas. Vol 12.

Ivancevich dan Matteson, 1999, Human Resources Management, 6th ed, Irwin, Chicago.

Kouzes, James M. and Barr Z. Posner. 1993. Credibility, How Leaders Gains and Lose it, Why People Deman it. Jessy-Bases, Inc.

Lako, Andreas. 2004. Kepemimpinan dan Kinerja Organisasi: Isu, Teori dan Solusi. Yogyakarta: Amara Books.

Lowney,C.2005. Heroic Leadership: Praktik Terbaik Sebuah Perusahaan Berumur 450 Tahun yang Mengubah Dunia. Alih Bahasa Rusli,R.A. Jakarta:Gramedia

Mangkunegara, Anwar Prabu. 2005. Perilaku dan Budaya Organisasi. Bandung: PT. Rafika Aditama.

Moorhead,G and W.G. Ricky. 1999. Human Recources Management. $7^{\text {th }}$ Edition. New York: Prentice Hall,Inc 
Nawawi, H. 2003. Kepemimpinan Mengefektifkan Organisasi. Yogyakarta: Gajah Mada Press.

Newstrom, John W.and Keith Davis. 2005. Organizational Behaviour: Human Behaviour at Work. Ninth Edition.McGraw-Hill Series.

Novliandi, F.2006. Organizational Citizenship Behaviour Karyawan Ditinjau dari Persepsi Terhadap Kualitas Interaksi Atasan-Bawahan dan Persepsi Terhadap Dukungan Organisasional. Psikologic, 2(1),39-46

Priyanto, Dwi. 2008. Mandiri Belajar SPSS. Mediakom. Yogyakarta.

Porter,L.R, Steers., R. Mowdays., and P.Boulian. 1998. Organizational Commitment, Job Statisfaction and Turnover Among Pschiatric Technicisian. Journal of Applied Pschology. Vol. 59. No.5.

Poznanski,Peter,J., and Blinc, Denni,M. 1997. Using Structural Equation Modelling to Investigate The Causal Ordering of Job Satisfaction and Organizational Commitment Among Staf Accountants. Behaviour Research in Accounting. Vol 9.

Rahmi, B Maptuthah. 2013. Pengaruh Kepemimpinan Transformasional terhadap Organizational Citizenship Behavior dan Komitmen Organisasional dengan Mediasi Kepuasaan Kerja.Tesis Program Pascasarjana Universitas Udayana Denpasar.

Robbin dan Judge. 2006. Perilaku Organisasi (Organizational Behavior). Salemba Empat; Jakarta

Robbins, Stephen.P and Coulter, Mary. Management. Ninth Edition. New York: Prentice Hall.

Sugiyono. 2011. Metode Penelitian Pendidikan. Alfabeta. Bandung.

Suliyanto. 2006. Metode Riset Bisnis. Penerbit Andi. Yogyakarta.

Sunjoyo, dkk. 2013. Aplikasi SPP Untuk Smart Riset. Alfabeta. Bandung.
Tampubolon, Mahanan, P. 2004. Perilaku Organisasi. Jakarta: Ghalia Indonesia.

Tika, Prabundu, H.Moh. 2006. Budaya Organisasi dan Peningkatan Kinerja Perusahaan. Jakarta: PT. Bumi Aksara.

Triguno. 2000. Budaya Kerja. Jakarta: Golden Trayon Prsess.

Widuri, Rindang dan Paramita, Asteria. 2007. Analisis Hubungan Peranan Budaya Perusahaan Terhadap Penerapan Good Corporate Governance pada PT. Aneka Tambang Tbk. Journal The Winners.Vol 8. No.2. Hal: 126-138 